\title{
The first historical account of Vietnam mathematics research on arXiv
}

\author{
Ho Manh Toan \\ The Centre for Interdisciplinary Social Research (ISR) \\ Phenikaa University, Hanoi, Vietnam
}

November 20, 2020

http://isr.phenikaa-uni.edu.vn/chitiet/tin-tuc 2019222758 84/the-first-historicalaccount-of-vietnam-mathematics-research-on-arxiv

To celebrate Vietnam Teachers' Day, the VIASM SciMath Database Project team members have completed the first working draft, depicting the 80-year development history of Vietnam mathematical research.

The 100-page preprint was accepted by arXiv on November 19 and has since been online at https://arxiv.org/abs/2011.09328.

\begin{tabular}{|c|c|c|}
\hline \multirow{2}{*}{\multicolumn{2}{|c|}{$\begin{array}{l}\text { (囯语) Cornell University } \\
\text { arXiv.org > cs > arXiv.2011.09328 }\end{array}$}} & $\begin{array}{l}\text { We gratefully acknoy } \\
\text { the Simons Foundation and }\end{array}$ \\
\hline & & All fields \\
\hline \multicolumn{2}{|c|}{ Computer Science > Digital Libraries } & \\
\hline \multirow{2}{*}{\multicolumn{2}{|c|}{$\begin{array}{l}\text { The } 80 \text {-year development of Vietnam mathematical research: Preliminary insights from the SciMath } \\
\text { database on mathematicians, their works and their networks }\end{array}$}} & $\begin{array}{l}\text { - PDF only } \\
(\infty) \text { EY }^{-}\end{array}$ \\
\hline & & Current browse : \\
\hline \multirow{3}{*}{\multicolumn{2}{|c|}{$\begin{array}{l}\text { Starting with the first international publication of Le Van Thiem in 1947, modern mathematics in Vietnam is a longstanding research field. However, what is known } \\
\text { about its development usually comes from discrete essays such as anecdotes or interviews of renowned mathematicians. We introduce SciMath-a database on } \\
\text { publications of Vietnamese mathematicians. To ensure this database covers as many publications as possible, data entries are manually collected from scientists' } \\
\text { publication records, journals' websites, universities, and research institutions. Collected data went through various verification steps to ensure data quality and } \\
\text { minimize errors. At the time of this report, the database covered } 8372 \text { publications, profiles of } 1566 \text { Vietnamese, and } 1492 \text { foreign authors since 1947. We found a } \\
\text { growing capability in mathematics research in Vietnam in various aspects: scientific output, publications on influential journals, or collaboration. The database and } \\
\text { preliminary results were presented to the Scientific Council of Vietnam Institute for Advanced Study in Mathematics (VIASM) on November 13th, 2020. }\end{array}$}} & $\begin{array}{l}<\text { prev I } \quad n \\
\text { new | recent | } 2 C \\
\text { Change to brows } \\
\text { cs } \\
\text { math } \\
\quad \text { math.HO }\end{array}$ \\
\hline & & $\begin{array}{l}\text { References } 8 \\
\text { - NASA ADS } \\
\text { - Google Schc } \\
\text { Semantic Sc }\end{array}$ \\
\hline & & Export Bibtex \\
\hline $\begin{array}{l}\text { Subjects: } \\
\text { Cite as: }\end{array}$ & $\begin{array}{l}\text { Digital Libraries (cs.DL); History and Overview (math.HO) } \\
\text { arXiv.2011.09328 [cs.DL] } \\
\text { (or arXiv.2011.09328v1 [cs.DL] for this version) }\end{array}$ & 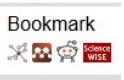 \\
\hline \multicolumn{3}{|c|}{ Submission history } \\
\hline \multicolumn{3}{|c|}{$\begin{array}{l}\text { From: Manh Toan Ho Mr. [view email] } \\
\text { [v1] Wed, } 18 \text { Nov } 2020 \text { 15:06:38 UTC (1,592 KB) }\end{array}$} \\
\hline
\end{tabular}

https://arxiv.org/abs/2011.09328 [1]

The SciMath project had been jointly discussed and conceived by Prof. Ngo Bao Chau (the University of Chicago and the Vietnam Institute for Advanced Study in Mathematics) and Dr. Vuong Quan Hoang (ISR, Phenikaa University) before having been officially supported by The 
Phenikaa Innovation Foundation, following the agreement between Prof. Ngo Bao Chau and Dr. Ho Xuan Nang (Phenikaa Chairman).

The database project's actual implementation course has taken ISR research staff and outside volunteers roughly 13 months to reach this first English-language working paper. The preceding Vietnamese version of this manuscript was presented at VIASM Scientific Council Meeting on November 13, 2020, during which top mathematicians such as Profs. Ngo Bao Chau, Ho Tu Bao, Vu Ha Van, to name just a few, praised the intrepid efforts and congratulated the project team on the first achievement.

The project represents a daunting task of constructing the SciMath database, the first of its kind, covering the whole modern history of Vietnam mathematics by applying the analytical lenses on the authors-works-networks data sets. The whole project implementation also has to meet difficult criteria set out by Dr. Hoang's principle [2] of balancing cost-efficiency and value of scientific information within a strict timespan.

\section{References}

[1] NB Chau, VQ Hoang, LV Phuong, LT Hoa, LM Ha, et al. (2020). The 80-year development of Vietnam mathematical research: Preliminary insights from the SciMath database on mathematicians, their works and their networks. arXiv:2011.09328. https://arxiv.org/abs/2011.09328

[2] QH Vuong. (2018). The (ir)rational consideration of the cost of science in transition economies. Nature Human Behaviour 2(1):5. 